\title{
STUDI KOMPARATIF HASIL BELAJAR BIOLOGI DIDASARKAN PADA PERSEPSI SISWA TERHADAP IKLIM KELAS (CLASSROOM ENVIRONMENT SCALE/CES): STUDI EX POST FACTO PADA SISWA DI SMAN 1 JAKARTA
}

\author{
Comparative Study of Biology Learning Outcomes Based \\ on the Student's Perceptions of Classroom Climate \\ (Classroom Environment Scale/CES): \\ Ex Post Facto Study on Students of 1 High School Jakarta
}

Diana Vivanti Sigit, I Made Putrawan, Claudia Sulfitania

Pendidikan Biologi/Biologi Fakultas MIPA Universitas Negeri Jakarta

Email: dianavivanti@yahoo.com

\begin{abstract}
Learning is closely associated in determining student learning outcomes. In the process of teaching and learning, teachers have an important role in the achievement of learning goals. One indicator of achievement learning goals can be seen from the results of student learning outcomes. Teachers belonging to the environmental conditions or climate. Student's perceptions of classroom climate greatly affect student learning outcomes. The purpose of this research was to determine differences in biology of learning outcomes based on student's perceptions of classroom climate (Classroom Environment Scale/CES). This research was held in 1 High School Jakarta on April-May 2016. This type of research was quantitative with ex post facto method through comparative studies. The subjects of research were students of class X IPA with a total sample of 54 students were selected by Simple Random Sampling. Data collection techniques by using achievement test biological and Classroom Environment Scale (CES). The analysis prerequisite test was used the test for normality with the Kolmogorov-Smirnov test and homogeneity test with F-test. Based on the calculations, data were normally distributed and homogeneous. Hypothesis testing was done through t-test. The results of the t-test for biology learning outcomes shows that there was differences between biology learning outcomes both positive and negative student's perceptions of classroom climate (Classroom Environment Scale/CES).
\end{abstract}

Keywords : Biology learning outcomes, Student's perceptions, Classroom climate, Classroom Environment Scale (CES)

\section{PENDAHULUAN}

Pembelajaran sangat erat kaitannya dalam menentukan hasil belajar siswa. Dalam proses belajar mengajar, guru memiliki peranan penting dalam tercapainya tujuan pembelajaran. Salah satu indikator tercapainya tujuan pembelajaran dapat dilihat dari hasil belajar siswa yang terkait dengan bagaimana kemampuan guru dalam berkreativitas mengemas suatu pelajaran agar siswa lebih tertarik mengikuti pelajaran sehingga hasil belajar siswa 
semakin meningkat. Hasil belajar siswa akan maksimal apabila guru dapat menciptakan situasi dan kondisi proses pembelajaran kondusif di kelas. Oleh karena itu, guru sangat menentukan keberhasilan proses pembelajaran di kelas. Jadi, guru termasuk ke dalam kondisi proses pembelajaran di lingkungan atau iklim kelas.

Iklim kelas adalah segala situasi yang muncul akibat hubungan antara guru dan siswa atau hubungan antara siswa yang menjadi ciri khusus dari kelas dan mempengaruhi proses belajar mengajar. (Hadiyanto dan Subijanto, 2003).

Ada tiga dimensi umum iklim kelas yang kemudian menjadi panutan para ahli tentang iklim kelas Ketiga dimensi tersebut adalah dimensi hubungan (relationship), dimensi pertumbuhan dan perkembangan pribadi (personal growth atau goal orientation) serta dimensi perubahan dan perbaikan sistem (system maintenance and change). (Fisher, 1990). Dimensi-dimensi ini terdapat dalam suatu alat ukur iklim kelas yang dinamakan Classroom Environment Scale (CES) atau skala iklim kelas.

Iklim kelas sangat mempengaruhi hasil belajar siswa. Hal ini beralasan karena ketika para siswa belajar di ruangan kelas, lingkungan atau iklim kelas, baik itu lingkungan fisik maupun non-fisik kemungkinan mendukung mereka atau justru mengganggu mereka. Dengan adanya iklim kelas yang baik, maka persepsi siswa mengenai iklim kelasnya akan positif sehingga memacu siswa dan akan berpengaruh terhadap hasil belajar siswa.

Persepsi positif siswa terhadap iklim kelas ditandai oleh hubungan sosial kelas yang dinamis, akrab dan kompak, serta keadaan fisikal kelas yang memudahkan terjadinya dinamika belajar siswa. Namun, persepsi negatif siswa terhadap iklim kelas ditandai oleh kondisi kelas yang terganggu, misalnya terjadi konflik terbuka antara beberapa siswa saat proses belajar berlangsung, kelas gaduh akibat adanya perilaku menyimpang dari beberapa siswa, siswa masuk kelas dengan menunjukkan tingkah laku yang tidak disiplin, serta keadaan kelas yang tegang.

Dengan demikian persepsi siswa terhadap iklim kelas tersebut menjadi penting diteliti karena akan memberi informasi yang sangat penting bagi pengembangan kemampuan guru dalam meningkatkan hasil belajar siswa. Perbedaan hasil belajar siswa akan tampak karena adanya pengaruh persepsi positif dan negatif siswa terhadap iklim kelas. Atas dasar pemikiran tersebut, maka perlu dilakukan penelitian mengenai studi komparatif hasil belajar biologi didasarkan pada persepsi siswa terhadap iklim kelas (Classroom Environment Scale/CES).

Tujuan penelitian ini adalah mengukur perbedaan hasil belajar biologi didasarkan pada persepsi siswa terhadap iklim kelas (Classroom Environment Scale/CES).

\section{METODE}

Penelitian ini menggunakan metode ex post facto melalui studi komparatif. Variabel bebas (X) pada penelitian ini adalah persepsi siswa terhadap iklim kelas (Classroom Environment Scale/CES), sedangkan variabel terikat (Y) adalah hasil belajar biologi. Penelitian ini dilaksanakan di SMA Negeri 1 Jakarta, pada bulan April-Mei 2016. Sampel yang digunakan pada penelitian ini adalah 54 siswa SMAN 1 Jakarta yang ditentukan dengan cara simple random sampling. 


\section{PROSEDUR ANALISIS DATA}

Pada penelitian ini uji prasyarat analisis data meliputi uji normalitas dan uji homogenitas. Uji normalitas data dilakukan dengan menggunakan uji Kolmogorov-Smirnov pada $\alpha=0,05$. Uji normalitas digunakan untuk mengetahui apakah sampel berdistribusi normal atau tidak. Sedangkan uji homogenitas diperoleh dari perbandingan kuadrat simpangan baku (varian) terbesar dan terkecil menggunakan uji $\mathrm{F}$ dengan $\alpha=0,05$. Setelah uji prasyarat terpenuhi, selanjutnya adalah pengujian hipotesis. Uji hipotesis yang digunakan dalam penelitian ini adalah pengujian perbedaan dua rata-rata dengan uji-t independent two tailed pada $\alpha=0,05$. Hal ini karena kedua kelompok (siswa yang memiliki persepsi positif dan siswa yang memiliki persepsi negatif) sampel berasal dari kelompok yang tidak saling berhubungan (independen).

\section{HASIL DAN PEMBAHASAN}

Data hasil penelitian berupa skor dari masing-masing variabel yang diteliti, yaitu persepsi siswa terhadap iklim kelas (Classroom Environment Scale/CES) sebagai variabel bebas dan hasil belajar biologi sebagai variabel terikat. Pengambilan data persepsi siswa terhadap iklim kelas yaitu berupa instrumen CES dan pengambilan data hasil belajar biologi berupa instrumen tes soal tentang ekosistem.

\section{Hasil}

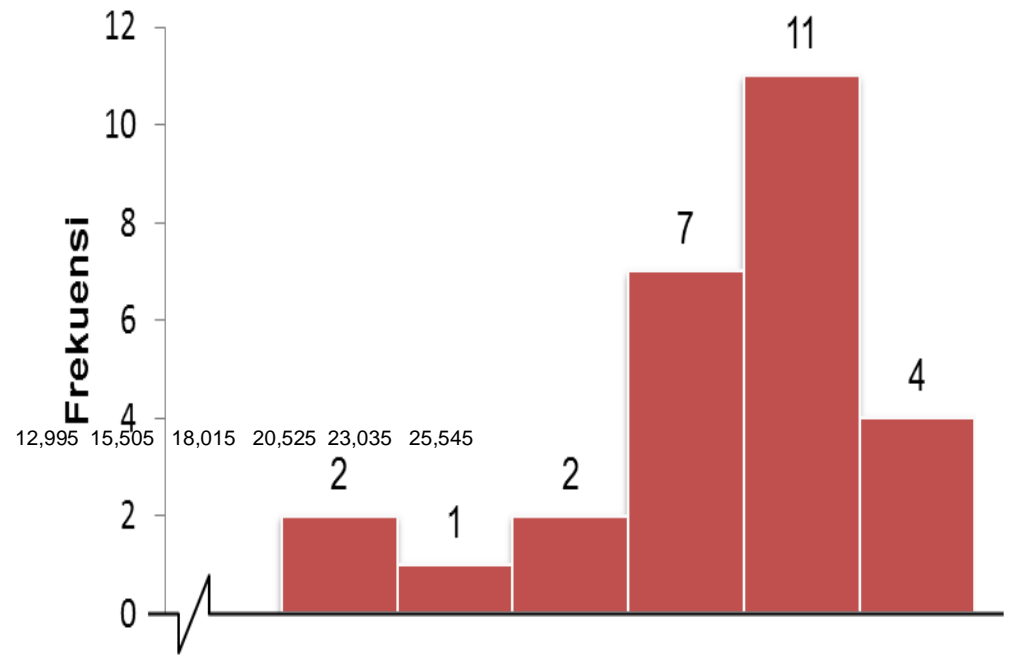

\section{Rentang Skor}

Gambar 1. Histogram Distribusi Frekuensi Skor Hasil Belajar Kelompok Persepsi Positif Siswa terhadap CES. 


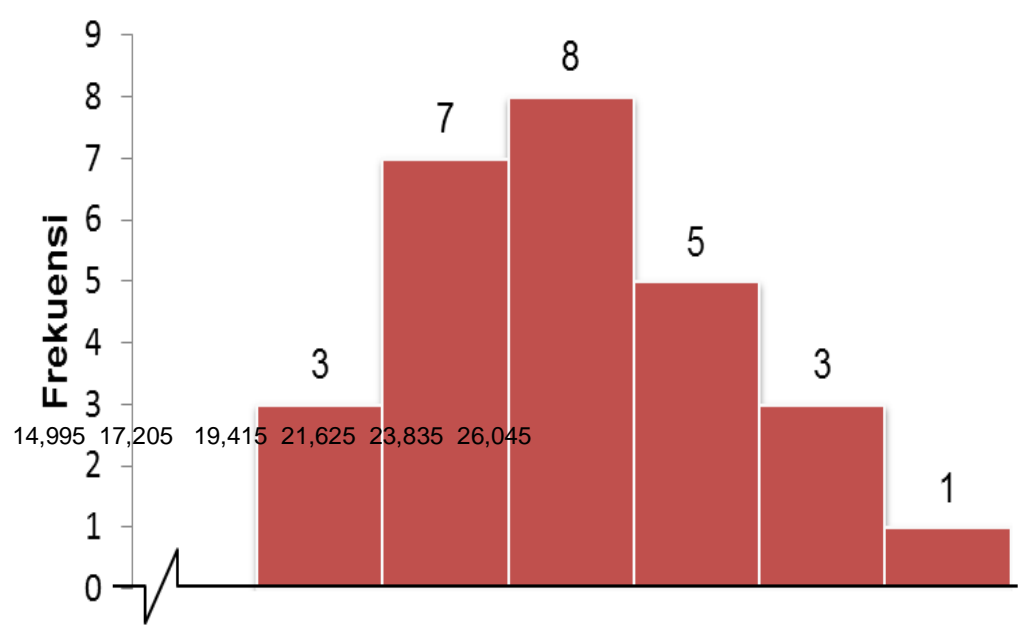

\section{Rentang Skor}

Gambar 2. Histogram Distribusi Frekuensi Skor Hasil Belajar Kelompok Persepsi Negatif Siswa terhadap CES

Tabel 1. Uji-t independent two tailed $\mathrm{t}$ antara kelompok persepsi positif dengan kelompok persepsi negatif siswa terhadap CES

\begin{tabular}{|c|c|c|c|c|}
\hline $\mathrm{n}$ & $\mathrm{df}$ & $\bar{X}-\bar{Y}$ & $\mathrm{t}_{\text {hitung }}$ & $\mathrm{t}_{\text {tabel }}(\alpha=0,025)$ \\
\hline 54 & 52 & $22,93-20,52$ & $2,24^{*}$ & 2,00 \\
\hline
\end{tabular}

Keterangan:

$$
*=\mathrm{p}<0,05
$$

\section{PEMBAHASAN}

Berdasarkan uji beda dengan perhitungan uji t, antara persepsi positif dan negatif siswa terhadap CES untuk hasil belajar biologi terdapat perbedaan. Hasil hitung uji t yang didapat adalah 2,24. Angka tersebut bernilai lebih besar jika dibandingkan dengan $t_{\text {tabel }}$ yang bernilai 2,00.

Berdasarkan hasil penelitian, skor hasil belajar biologi siswa berbeda-beda, baik yang memiliki persepsi positif dan negatif terhadap iklim kelas (Classroom Environment Scale/CES). Siswa yang memiliki persepsi positif terhadap iklim kelas menghasilkan hasil belajar biologi yang lebih baik dibandingkan siswa yang memiliki persepsi negatif terhadap iklim kelas. Hal ini dikarenakan ratarata hasil belajar biologi siswa yang memiliki persepsi positif terhadap iklim kelas lebih tinggi dibandingkan rata-rata hasil belajar biologi siswa yang memiliki persepsi negatif terhadap iklim kelas. Kondisi tersebut sesuai dengan teori bahwa iklim kelas sangat berpengaruh terhadap hasil belajar siswa. Hal ini dikarenakan dimensi-dimensi dari persepsi siswa terhadap iklim kelas (Classroom Environment Scale/CES) yang diterapkan oleh guru akan meningkatkan motivasi siswa sehingga mempengaruhi hasil belajar siswa.

Kondisi siswa yang memiliki persepsi positif terhadap iklim kelas ditandai oleh adanya keterlibatan yang aktif antara guru dengan siswa, dan juga antara 
siswa dengan siswa. Hal ini dikarenakan siswa mempersepsikan positif terhadap iklim kelas antara lain guru tersebut memotivasi siswa, mengevaluasi siswa, memberikan inspirasi kepada siswa, memberikan reward bagi siswa yang berhasil mengerjakan tugas, meningkatkan disiplin siswa, mengajarkan siswa secara tidak monoton, menggunakan teknologi pembelajaran yang modern dan canggih, serta mendorong siswa untuk selalu mencari tahu melalui web/internet. Selain itu, hubungan siswa dengan siswa meliputi kerjasama siswa dan kekompakan siswa. Jadi, kondisi ini akan dipersepsi oleh siswa dan berdampak positif pada hasil belajar siswa.

Namun, kondisi siswa yang memiliki persepsi negatif terhadap iklim kelas akan ditandai oleh adanya hubungan kondisi kelas yang terganggu, misalnya terjadi konflik terbuka antara beberapa siswa saat proses belajar berlangsung, kelas gaduh akibat adanya perilaku menyimpang dari beberapa siswa, serta siswa masuk kelas dengan menunjukkan tingkah laku yang tidak disiplin. Hal ini dikarenakan siswa mempersepsikan negatif terhadap iklim kelas antara lain guru tersebut kurang mendorong siswa agar saling membantu sesama, kurang meningkatkan disiplin siswa, cara mengajar yang monoton, dan tidak mengevaluasi siswa secara adil dan berkelanjutan. Selain itu, hubungan siswa dengan siswa kurang baik sehingga menyebabkan kelas terlihat gaduh. Jadi, kondisi ini akan dipersepsi oleh siswa dan berdampak negatif pada hasil belajar siswa.

Perbedaan hasil belajar siswa berdasarkan persepsi siswa terhadap iklim kelas, hal ini relevan dengan penelitian sebelumnya (Shinta, 2007) dimana terdapat perbedaan yang signifikan antara prestasi belajar siswa putra dan putri berdasarkan persepsi siswa terhadap iklim lingkungan kelas.

Persepsi siswa mengenai iklim kelas akan berpengaruh pada hasil belajar siswa itu sendiri. Hal ini seperti yang diungkapkan oleh Syamsu Yusuf (2007) yang mengatakan bahwa "karakteristik pribadi dan kompetensi guru sangat berpengaruh terhadap iklim kelas, proses pembelajaran di kelas, atau hubungan guru-siswa pada gilirannya akan berpengaruh juga pada hasil belajar siswa."

Kemudian Berliner yang dikutip Hadiyanto dan Subijanto mengatakan bahwa "Iklim kelas yang ditandai dengan kehangatan, demokrasi, dan keramahtamahan dapat digunakan sebagai alat untuk memprediksi hasil belajar siswa.".Selain itu untuk memperkuat pandangan di atas, Fraser (1986) meneliti lebih dari 45 penelitian yang membuktikan adanya hubungan yang positif antara iklim kelas dengan prestasi belajar siswa. Studi-studi itu menunjukkan bahwa siswa yang belajar dalam iklim kelas yang mereka kehendaki memperoleh prestasi belajar yang lebih baik dibandingkan dengan mereka yang belajar dalam iklim kelas yang tidak cocok.

Maka untuk meningkatkan hasil belajar siswa, guru harus menerapkan dimensi-dimensi CES (Classroom Environment Scale) dalam proses pembelajaran dimensi CES tersebut antara lain dimensi hubungan (relationship), dimensi pertumbuhan dan perkembangan pribadi (personal growth atau goal orientation) dan dimensi perubahan dan perbaikan sistem (system change and maintenance). 


\section{KESIMPULAN}

Berdasarkan temuan dalam penelitian ini menunjukkan bahwa terdapat perbedaan hasil belajar biologi antara persepsi positif dan negatif siswa terhadap iklim kelas (Classroom Environment Scale/CES).

\section{DAFTAR PUSTAKA}

Fisher, Darrell L. (1990). The Assessment and Change of Classroom and School Environment. Launceston: Tasmanian State Institute of Technology.

Fraser, BJ. (1986). Classroom Environment. London: Croom Helm.

Hadiyanto dan Subijanto. (2003). "Pengembalian Kebebasan Guru untuk Mengkreasi Iklim Kelas dalam Manajemen Berbasis Sekolah (MBS)”. Jurnal Kependidikan dan Kebudayaan. No. 40. Tahun Ke-9.

Susanty, Shinta. (2007). "Iklim Lingkungan Kelas Mempengaruhi Prestasi Akademik". Jurnal Provite. Vol 3, No. 1.

Yusuf, Syamsu. (2007). Psikologi Perkembangan Anak dan Remaja. Bandung: Remaja Rosdakarya. 